\title{
Parroquias y diezmos en la historiografía medieval española*
}

\author{
Parishes and tithes in Spanish medieval historiography
}

\author{
Carla Cimino \\ carlacimino@hotmail.com \\ Becaria doctoral \\ Universidad Nacional de La Plata \\ Calle 51 e/ 124 y 125 . Oficina C325 - Ensenada \\ 1925 - Buenos Aires \\ Argentina
}

\section{Resumen}

El presente trabajo analiza los principales debates de la historiografía medieval ibérica sobre el problema de los diezmos y las iglesias rurales. Se trata de un tema que ha recibido mucha atención durante el siglo XX y que es fundamental para comprender la estructura del señorío catedralicio y la reproducción material del clero secular. Así, se hace necesario repasar la producción historiográfica más importante buscando demostrar que los estudios ibéricos estuvieron muy influenciados por la historiografía francesa. Dicha influencia fue orientando el interés de los historiadores hacia ciertos aspectos del tema, lo que supuso el abandono de otros. Dividimos el trabajo en tres grandes secciones: los estudios jurídico-institucionales, la historia social clásica y los trabajos sobre la organización social del espacio. Buscamos explorar los logros y los límites de cada una de las visiones, identificar los problemas que aún quedan por abordar y destacar los aportes de cada una de esas escuelas para un estudio renovado del problema.

\section{Palabras clave}

Historiografía del siglo XX; Historia Medieval; Península Ibérica.

\begin{abstract}
This paper analyzes the main debates of Iberian medieval historiography on the issue of tithes and rural churches. The subject has received much attention during the twentieth century and remains essential for analyzing the structure of cathedral lordship, while it is also the starting point for understanding the material reproduction of secular clergy. It is thus necessary to review the most important studies seeking to demonstrate that Iberian scholars were largely influenced by French historiography. Such influence directed the interest of historians towards studying certain aspects of the subject, while abandoning others. We divided the work into three sections that correspond to the development of the historical discipline: legal-institutional studies, classic social history and the work on social organization of space. We seek to explore the achievements and limits of each of the views, to identify problems that remain to be addressed and to highlight the contributions of each of these schools to a renewed study on the subject.
\end{abstract}

Keywords

$20^{\text {th }}$ century historiography; Medieval history; Iberian Peninsula.

Recibido el: 2/11/2013

Aprobado el: 6/2/2014

* Investigación financiada por el Consejo Nacional de Investigaciones Científicas y Técnicas. 
Hace ya mucho tiempo que, en una obra de gran influencia, Duby destacaba la importancia del diezmo entre los ingresos de los señores en la plena Edad Media. El diezmo, indicaba, era uno de los recursos más preciados para los señores laicos y eclesiásticos, pues les permitía apropiarse de manera indirecta de los beneficios del crecimiento económico (DUBY 1999a, p. 279). Su afirmación añadía una razón más a la gran atención que, desde una u otra perspectiva, siempre había recibido el tema. Ya sea en el marco del estudio de la historia de la Iglesia, tradicionalmente abordada desde una perspectiva institucional-jurídica asociada a la reforma gregoriana, o en el del más reciente "enceldamiento", la organización de la red parroquial y la recaudación y distribución de diezmos han sido objeto de gran cantidad de trabajos. Sobre todo dos cuestiones han Ilamado la atención de los historiadores: en primer término, la apropiación privada de iglesias y su posterior transferencia a la tutela eclesiástica; en segundo lugar, el rol de las parroquias en la organización interna de la comunidad, en la definición de su identidad y en la fijación de marcos territoriales más rígidos que los de la aldea o el señorío.

Las parroquias poseen gran importancia para la comprensión de la estructura del señorío episcopal. Durante mucho tiempo se ha estudiado esa forma señorial apelando a los modelos construidos sobre los señoríos monásticos. Aunque, sin dudas, existen aspectos en los que ambos se asemejan mucho (especialmente las formas de explotación de la tierra), hay elementos particulares del señorío episcopal que lo diferencian: desde los siglos centrales de la Edad Media, la renta decimal adquiere una relevancia creciente para el sostén de las catedrales. ${ }^{1}$ Se trata de una renta atada a los rendimientos de la cosecha y cuya percepción se realiza aún antes de detraer la simiente. Sus modalidades de obtención y gestión condicionan la administración catedralicia y el accionar de los miembros del clero secular, que perciben y administran sus rentas de forma diferente a los monjes. El intento de comprender la reproducción material de la nobleza eclesiástica, especialmente del clero secular, a partir del conocimiento de la estructura del señorío catedralicio requiere, entonces, partir de la célula básica de recaudación tributaria de los episcopados.

Antes de abordar el análisis empírico, el presente trabajo repasa la producción historiográfica más relevante para el ámbito ibérico desde principios del siglo pasado, poniendo de relieve la importante influencia que ejerció la historiografía francesa sobre los autores españoles. Para eso, se comentan los aportes principales agrupándolos en tres grandes grupos de trabajos: los de la historiografía tradicional, de orientación institucional y fuertemente influida por la erudición católica; los de la historia social y económica clásica, en los cuales son determinantes las influencias del marxismo y de la escuela de Annales; y los de la moderna historiografía sobre las transformaciones del hábitat, marcada por la renovada fortaleza de la historia religiosa. Esta última, actualmente dominante, integra la preocupación por la problemática del poder

\footnotetext{
${ }^{1}$ Es un tema que ha llamado la atención de los historiadores, como lo demuestran dos recientes coloquios de relevancia internacional: las XXX Jornadas de la Abadía de Flarán y el Congreso sobre Iglesia y Fiscalidad, organizado por la Casa de Velázquez, ambos en 2008.
} 
definida en términos foucaultianos, con una revalorización del lugar de la Iglesia en la sociedad medieval. Las tres orientaciones han aportado gran cantidad de información, incorporando las iglesias rurales al marco problemático que dominaba el debate historiográfico en el que participaron.

Más cerca del objeto de nuestra propia investigación, evaluamos el tratamiento del tema por parte de los historiadores ibéricos que analizaron la documentación de las catedrales de la Extremadura castellano-leonesa. Buscamos argumentar que, aunque la documentación es abundante y las iglesias rurales poseen un rol destacado en la constitución y reproducción del señorío de las catedrales del área, los autores no prestaron especial atención al tema. Volvemos, entonces, a la afirmación de Duby, pues entendemos que sus implicancias no han sido cabalmente sopesadas al abordar el estudio del señorío de las catedrales castellano-leonesas. Si las parroquias se constituyeron en tan importante centro de recaudación de rentas, deberíamos reconsiderar con cautela su lugar en el patrimonio catedralicio teniendo en cuenta el agresivo proceso de acumulación de derechos que encararon los obispos durante los siglos centrales de la Edad Media.

\section{Los estudios jurídico-institucionales y la historia de la Iglesia}

Una de las primeras contribuciones de la historiografía profesional al estudio de las iglesias rurales en la Edad Media puede encontrarse en los historiadores del derecho y las instituciones, sobre todo en los interesados en la historia de la Iglesia. Ellos abordaron el tema de la apropiación de diezmos partiendo del problema previo de la privatización de iglesias. La perspectiva cristiana de esos autores los condujo, por lo general, a entender el fenómeno como una anomalía, una desviación propia de una época en la que la Iglesia se hallaba dominada por poderes e intereses ajenos a ella.

Los trabajos más tempranos sobre las iglesias rurales se entroncan con la polémica entre romanistas y germanistas. El historiador alemán Ulrich Stutz había señalado que las iglesias de particulares, comunes en la alta Edad Media, tenían su razón de ser en las más arraigadas tradiciones germanas. Los germanos - sostenía - solían construir templos en sus dominios para honrar a los dioses paganos, los cuales formaban parte de su patrimonio al igual que otros bienes y edificios. Habrían obtenido la contribución de los vecinos que no podían erigir los suyos y que colaboraban con el mantenimiento del templo al que acudían (STUTZ 1895a; 1895b). El derecho del propietario sobre parte de los templos derivaba, entonces, de antiguas costumbres que reposaban en última instancia sobre la propiedad fundiaria de quien edificara la iglesia.

Frente a esa postura aparecía la de Pierre Imbart de la Tour, quien publicó un importante estudio en el cual defendía la estrecha relación existente entre el orden señorial y las iglesias propias. Dicho autor indicó que la decadencia de las iglesias "libres" y su caída en manos de los poderosos tenían su razón de ser en el contexto de crisis de los poderes públicos e inestabilidad política que siguió a la caída del orden romano (IMBART DE LA TOUR 1900, p. 190 y ss.). Insistió sobre todo en dos aspectos: el encargo de propiedades a los poderosos 
y las usurpaciones y violencias de los siglos IX y X (IMBART DE LA TOUR 1900, p. 207). La búsqueda de protección para las iglesias y sus bienes habría hecho recaer en los reyes primero y luego en los señores la potestad de defenderlas. La protección pronto derivó en propiedad, cuando la misma violencia dio lugar a la profundización de los vínculos con sus protectores (IMBART DE LA TOUR 1900, p. 212). Así, el disfrute de los diezmos por parte de los particulares posee su origen en dichos actos de violencia y en la alteración de la naturaleza de una entrega que, en su origen, había sido destinada al sustento del culto (IMBART DE LA TOUR 1900, p. 153).

A esa obra respondió la de Paul Thomas, aparecida poco tiempo después e interesada en analizar de forma detallada la transformación de la propiedad laica sobre las iglesias en patronato a partir de las reformas promovidas por Gregorio VII. El autor se pronunció, no obstante, acerca del origen de dicha propiedad laica sobre las iglesias. Desde su punto de vista, fue la propiedad sobre el suelo la que confirió el derecho a su apropiación (THOMAS 1906, p. 34). Esa fue también la razón de que se otorgara a los fundadores de iglesias el derecho de presentación del clérigo. El autor cuestionó así la importancia que Imbart otorgaba a la violencia nobiliaria del siglo X, destacando, en cambio, el lugar de la propiedad de la tierra (aunque, a diferencia de Stutz, no creía que eso fuese privativo de los germanos). Este punto es importante en su argumentación, pues sustenta su explicación del surgimiento del ius patronatus.

El derecho de patronato, novedad del siglo XI, sustituyó al de propiedad 92 en la definición de la relación entre los laicos y las iglesias. Según Thomas, la distancia entre ambos criterios era abismal: mientras el primero se entendía como gracia especial que otorgaba la Iglesia al fundador de un templo, el segundo implicaba gran cantidad de derechos y una importante capacidad de intervención de los laicos sobre la iglesia, sus rentas y su patrimonio. La consolidación del derecho de patronato como un derecho personal, derivado del acto de fundación, permitió a la Iglesia intervenir con el afán de limitar, o al menos supervisar, las enajenaciones, las cesiones y la infeudación de iglesias. Hacia los siglos XII y XIII dicha concepción se había impuesto definitivamente tanto en la teoría como en la práctica (THOMAS 1906, p. 116-118) y eso explicaba el fortalecimiento de la Iglesia plenomedieval.

Poco tiempo después, Paul Viard retomaba el problema de los diezmos conjugando las visiones de Imbart de la Tour y de Thomas. Según Viard, la apropiación de los diezmos por parte de los señores derivaba tanto de actos de violencia y codicia como del sistema de construcción de iglesias privadas (VIARD 1909, p. 136-137; 207-208). Asumía, así, una posición intermedia.

La tesis de Stutz había encontrado eco entre los especialistas españoles: interesó a Hinojosa y, por su intermedio, a Torres López, que encontró en ella argumentos para explicar un fenómeno usual en la península ibérica: las "iglesias propias". ${ }^{2} \mathrm{~A}$ diferencia de lo que creía la mayor parte de los historiadores españoles

2 Stutz había sido también responsable del término "Eigenkirche", traducido al español por Torres López como "iglesia propia". 
contemporáneos, la iglesia propia era una institución común en toda la Europa medieval (TORRES LÓPEZ 1925). Contribuyó así Torres López a una de las tareas que propusiera Hinojosa: relacionar las instituciones españolas con las de las demás regiones europeas y abandonar la explicación histórica sustentada en las particularidades nacionales (MORÁN MARTÍN 2005; RODRÍGUEZ GIL 1999, p. 248). Sin embargo, los trabajos posteriores también influyeron en la visión de Torres López, quien, poco tiempo después de aparecido su primer texto, se alejó definitivamente de la tesis de Stutz tras tener en cuenta la documentación que había sustentado los trabajos de Imbart de la Tour y Thomas (MORÁN MARTÍN 2005, p. 11 y ss.; LORING GARCÍA 1987, p. 90). Consultando la legislación romana y bizantina, los decretos conciliares y las obras de los canonistas, Torres concluyó que las iglesias propias poseían un doble origen: fundadas en el derecho del propietario que erigiera el edificio de culto, se adaptaron al marco general de la alta Edad Media al lograr independencia de sus obispos, al igual que los monasterios (TORRES LÓPEZ 1928, p. 183 y ss.; RODRÍGUEZ GIL 1999, p. 257). En definitiva, fueron las prácticas señoriales las que condujeron al sistema de iglesias propias.

Los debates que involucraban a los historiadores de principios del siglo pasado versaban, como es evidente, sobre los orígenes de las iglesias de particulares, la precisión jurídica de los conceptos de propiedad y patronato, sobre la génesis de ambos y acerca del régimen de tenencia, percepción y distribución decimal. Los autores buscaban explicar la estrecha relación entre los señores y las iglesias patrimoniales. Sin distinguir entre laicos o eclesiásticos, condenaban el mero hecho de la propiedad privada sobre las iglesias como lo habían hecho los canonistas medievales. Al advertir sobre las consecuencias de la secularización iniciada en el siglo VII, los historiadores se pronunciaban sobre su propia época. En Francia, esos estudios quedaron sintetizados en los volúmenes de la Histoire de l'Église dirigida por Agustin Fliche y Victor Martin. La obra condensaba los aportes de la historiografía más importante y sus autores no omitían los juicios de valor: "No se hacía diferencia entre el dominium de un establecimiento eclesiástico y el de un laico. Era la misma perversión de lo sagrado por lo profano que acarreó los mismos abusos" (DUMAS 1948, p. 280, traducción nuestra). ${ }^{3}$

Del mismo modo que se condenaban las costumbres medievales se exaltaban los propósitos de la reforma gregoriana. Así como la propiedad y patrimonialización de las iglesias había supuesto una anomalía, su retroceso a partir de las transformaciones del siglo XI fue exaltado, entendido en términos de "liberación", "restauración". Para Gabriel Le Bras, la mayor responsable de dicha restauración había sido la reorganización eclesiástica basada en parroquias y diócesis (LE BRAS 1937, p. 496).

Es contemporánea la última obra específica sobre el tema aparecida en España: la tesis de Ramón Bidagor (1933). La obra se limitaba al estudio de

\footnotetext{
3 "On ne faisait pas de différence entre le dominium d'un établissement ecclésiastique et celui d'un laïque. C'était la même perversion du sacré par le profane qui entraîna les mêmes abus."
} 
las iglesias de particulares en el marco del derecho canónico, destacando la incongruencia entre aquellas y este. Sin buscar el origen de las iglesias de particulares ni considerar sus transformaciones, el autor estaba interesado en argumentar a posteriori la concepción de la reforma gregoriana y de la jurisprudencia eclesiástica moderna, incluso a costa de ignorar fuentes que lo contradecían (RODRÍGUEZ GIL 1999, p. 259-260). Por la estrechez de sus objetivos y la simpleza de su método, constituye el ejemplo más evidente de que esta óptica había derivado en un discurso cristiano apologético que se adecuaba a la coyuntura política que vivía esa nación.

Desde dichos discursos apologéticos hasta la más "neutra" historia de las instituciones, el trabajo de historiadores y eruditos españoles, frecuentemente clérigos, poseyó un marcado carácter endógeno durante los años más duros del franquismo. La composición de los cabildos y su estructura interna, la elaboración de estatutos, la dotación y obligaciones de los canónigos, en definitiva, el funcionamiento de la institución, dominó durante muchos años el panorama de la investigación (LOP OTIN 2003, p. 278).

\section{La historiografía económica y social clásica}

Mientras España ingresaba en la dictadura franquista, en Francia, Marc Bloch proyectaba La sociedad feudal. La historia de la Iglesia era allí campo exclusivo de historiadores cristianos, muchas veces clérigos, que se interesaban por el desarrollo de la institución y que no consideraban necesario comprender la sociedad medieval en su conjunto. El divorcio era especialmente evidente en cuanto a la historiografía de temática sociopolítica: su separación respecto a la historia de la Iglesia era tan grande que aquel historiador consideró necesario encargar al renombrado especialista en historia eclesiástica, Gabriel Le Bras, la elaboración de un volumen dedicado a complementar su visión de conjunto de la época medieval (LAUWERS 2010, p. 269). ${ }^{4}$ En efecto, se ha llegado a caracterizar la situación de la disciplina histórica francesa de la época como una verdadera división del trabajo historiográfico (LAUWERS 2010, p. 269-270).

La obra de Marc Bloch presentaba así un panorama de la sociedad medieval en el cual la Iglesia y las dinámicas eclesiásticas tenían escasa significación con relación a la reproducción material de la clase noble. ${ }^{5}$ Ese hecho probablemente fue determinante para que la posterior obra de Duby, casi completamente sustentada en documentación monástica y catedralicia, no considerase necesario establecer grandes distinciones entre la forma de reproducción material de la nobleza laica y eclesiástica. Duby reconocía explícitamente una gran deuda respecto de la geografía y la historia del derecho. Esa falta provenía tanto de su formación previa como de la influencia de Bloch (TOUBERT 1997, p. 68 y ss.), pero no sucedía lo mismo con la historia de la Iglesia. Dicha institución no tenía lugar en su tesis sobre el señorío banal ni en sus consideraciones sobre

\footnotetext{
${ }^{4}$ Se trata de L'Église et le village.

5 Esto no significa que el autor ignorase la relevancia de los fenómenos religiosos para la reproducción del poder de dicha clase o de algunos de sus sectores. Lo puso especialmente de relieve con relación a la monarquía en Los reyes taumaturgos.
} 
las dinámicas sociales fundamentales de la Edad Media (MAZEL 2008, p. 4). Ese vacío fue señalado por Lemarignier en una reseña de la tesis de Duby aparecida en 1956 (BOUGARD 2008, p. 12).

Esta última afirmación quizás resulte excesiva si tenemos en cuenta que Duby dedicó luego algunas páginas del que fue su primer trabajo a escala europea a analizar la relación entre los señoríos laicos y los eclesiásticos (DUBY 1999a, p. 230-246). En Economía rural y vida campesina... consideró las relaciones entre ambos sectores de la nobleza con respecto a los transvases de propiedad. Pese a la significación que poseen esas cuestiones, el interés de Duby apuntaba sobre todo al análisis del lugar del dominio y el señorío en el despegue económico europeo. Con ese objetivo en mente, poco importaba la división al interior de la clase nobiliaria: la naturaleza de la relación social básica no se veía alterada por ese factor. En cambio, consideró que la diferencia entre grandes y pequeños señores (monarcas, magnates u obispos, frente a caballeros, castellanos o canónigos), que poseían diferente vínculo con la producción agraria y el campesinado, era un elemento de primer orden (DUBY 1999a, p. 242-246; 293-301). La composición de la renta señorial variaba considerablemente con relación a ese factor, así como la actitud de los señores frente a la explotación de la tierra. Otro aspecto importante para la comprensión de la reproducción material de la clase señorial derivaba de la naturaleza territorial o banal de los elementos que componían la renta. Así, si bien dedicó numerosas páginas a la explotación del dominio, también indicó en reiteradas ocasiones que las banalidades y los diezmos proporcionaban a la nobleza las mejores rentas y eran, por eso, motivo de frecuentes conflictos con los campesinos o entre los mismos señores (DUBY 1999a, p. 279; 1999b, p. 282). Así, cada señorío podía poseer una estructura de ingresos y gastos diferente con relación a su dimensión, a su origen y a la procedencia de sus rentas. Tales indicaciones provenían de estudios de casos concretos, como el de la economía cluniacense (DUBY 1952) o el de los dominios de la Orden del Hospital en el sudeste de Francia (DUBY 1977). En este trabajo, por ejemplo, el autor observó en detalle la estructura de ingresos y gastos de los diferentes señoríos rurales a fin de realizar un balance de dicha estructura y comprender sus relaciones con las economías campesinas. Factores como la presencia - o ausencia- de reservas cultivables, la incidencia de los arrendamientos o los contratos de aparcería, la importancia de los censos y el volumen de los ingresos provenientes de las banalidades (hornos, molinos, diezmos, etc.) fueron contrastados con las necesidades derivadas del sostén señorial, del gasto en salarios o el mantenimiento de aperos y edificios. Duby indicó incluso que, dentro de un mismo dominio señorial, la estructura del ingreso y el gasto podía variar de señorío en señorío, por lo cual las conclusiones debían partir del reconocimiento de dichas variaciones (DUBY 1977, p. 116).

La de Duby fue, en definitiva, una obra de alcance europeo con una propuesta metodológica muy completa que obtuvo inmediata acogida en el ámbito ibérico. Se ha afirmado que, en un contexto de renovación historiográfica, la escuela de los Annales se presentaba como "radical en el estilo, pero académica en la forma y conservadora desde un punto de vista político" (FONTANA 2001, p. 
207). En una España que comenzaba a percibir el debilitamiento del franquismo, la incorporación de las relaciones entre clases a la historia económica no podía sino presentar dicha forma. En ese sentido, no es casual que Guerreros $y$ campesinos..., obra en la que Duby incorporó cierto número de elementos de la teoría marxista, ${ }^{6}$ no haya recibido igual atención que su libro anterior, que contiene tesis mucho más tradicionales.

García de Cortázar fue el primer historiador español en indagar los problemas planteados por Duby en la documentación ibérica. Tras analizar el marco espacial del monasterio de San Millán, la formación del dominio y los avatares de la historia político-militar del área, sus consideraciones sobre la estructura y explotación del dominio refieren permanentemente a los postulados de Duby. Aunque, años después, el autor parece haberlo olvidado (GARCÍA DE CORTÁZAR; MARTÍNEZ SOPENA 2008, p. 98-99), las referencias explícitas e implícitas son abundantes (GARCÍA DE CORTÁZAR 1969, p. 195-243). Los trabajos sobre dominios monásticos constituyeron, a partir de entonces, un género en sí mismo (REGLERO DE LA FUENTE 2010, p. 36-44). Guiados por los interrogantes que planteara Duby y contando con sistematizaciones conceptuales y propuestas metodológicas como la de Salustiano Moreta (1974), que incorporaba más abiertamente conceptos y problemas del marxismo, los historiadores ibéricos encararon la tarea de comprender la historia económica del período medieval en base a los fondos monásticos. ${ }^{7}$

Algunos contemporáneos reconocieron que el gran desarrollo de los trabajos sobre monasterios contrastaba con la escasa atención que había recibido en esos años la documentación catedralicia (MARTIN 1975, p. 53). Los trabajos basados en la documentación de las catedrales leonesas seguían enmarcados en una historia mucho más tradicional, interesada por la evolución institucional. La poca atención que recibieron los fondos catedralicios impidió a los historiadores de principios de los años 70 percibir el rol económico que desempeñaron los diezmos desde su generalización. Como lo indicaba José Luis Martín, los fondos monásticos no poseían demasiados datos sobre el diezmo. Así, esa importante fuente de renta debió esperar hasta la década siguiente para recibir la atención que merecía. La renovación historiográfica recién accedió a la documentación catedralicia en la década siguiente, cuando los historiadores comenzaban ya a apartarse del modelo de Duby y se acercaban a nuevas aproximaciones.

La década del 80 presenció dos importantes cambios en la orientación de las investigaciones sobre historia rural: por un lado, se abandonó poco a poco el modelo clásico del gran dominio para considerar el lugar central de la pequeña propiedad familiar en la economía medieval; por otro lado, la atención se centró cada vez más en la región, que reemplazó al dominio como objeto de análisis (GARCÍA DE CORTÁZAR; MARTÍNEZ SOPENA 2008, p. 104-105). Esas transformaciones se relacionaban con la decisiva influencia de los trabajos de

\footnotetext{
${ }^{6}$ Sobre las relaciones de la escuela de Annales con el marxismo, ver: ASTARITA 2009.

7 Para no abusar de la paciencia del lector, remitimos a los dos trabajos de síntesis citados para obtener referencias completas de la producción historiográfica sobre dominios monásticos (REGLERO DE LA FUENTE 2010; GARCÍA DE CORTÁZAR; MARTÍNEZ SOPENA 2008).
} 
Guy Bois y Pierre Toubert. Antes de considerar sus influencias, debemos repasar el tratamiento que las monografías de los años 80 dieron a la reproducción material de la clase señorial, concretamente a la nobleza eclesiástica, y el lugar que cupo a las rentas decimales en sus planteos.

Durante la década de 1980 aparecieron dos importantes tesis que abordaron el problema de la feudalización de Castilla y León partiendo de un análisis regional: en 1985, apareció la tesis de Pascual Martínez Sopena sobre Tierra de Campos (MARTÍNEZ SOPENA 1985) y, un año después, Luis Miguel Villar García publicó su trabajo sobre la Extremadura (VILLAR GARCÍA 1986). Ambas obras eran complementarias, a su vez, del trabajo de Ángel Barrios García sobre el Concejo de Ávila, aparecido poco tiempo antes (BARRIOS GARCÍA 1983/84). Los autores compartían un objetivo: demostrar que los territorios castellano-leoneses habían atravesado procesos de feudalización semejantes en su contenido, aunque no necesariamente idénticos en su forma, a los de otras áreas europeas. El análisis regional les llevó a indagar la evolución de formas señoriales diversas: monasterios, catedrales, las grandes familias de la aristocracia laica y el realengo (directo o concejil) aparecen como protagonistas centrales del proceso feudalizador, aunque con diferente relevancia según se trate de áreas al norte o sur del río Duero.

En cuanto a las catedrales del área, los trabajos demuestran un acusado interés por la constitución del señorío territorial. Aunque admiten que la pequeña producción tenía un lugar central en el área, ya sea por la dinámica de la expansión hacia el sur (BARRIOS GARCÍA 1983/84, p. 147; VILLAR GARCÍA 1986, p. 238 y ss.), o por la evolución de la gran propiedad (MARTÍNEZ SOPENA 1985, p. 229-247), el estudio de los procesos de acumulación y el análisis de la explotación de la gran propiedad adquieren un lugar central en todos los casos. Los autores coinciden en indicar que los procesos de acumulación patrimonial dependen fuertemente de las intervenciones de la monarquía, ya sea para dotar a las sedes del sur, de reciente fundación (BARRIOS GARCÍA 1983/84, p. 225 y ss.; VILLAR GARCÍA 1986, p. 228-233), o para favorecer la reorganización de la de León (MARTÍNEZ SOPENA 1985, p. 438-443).

Tras considerar la formación del dominio, los autores suelen contemplar el problema de su explotación. El modelo de Duby indicaba que la variable más importante para explicar la dinámica económica medieval venía dada por la relación entre la reserva señorial y las tenencias campesinas. En los casos ibéricos, la existencia de prestaciones de trabajo gratuitas era más difícil de identificar cuanto más se avanzaba hacia el sur. Así, lo que se hallaba constatado en Tierra de Campos (MARTÍNEZ SOPENA 1985, p. 241-244), se supuso para Ávila y Salamanca (BARRIOS GARCÍA 1983/84, p. 287-288; VILLAR GARCÍA 1986, p. 494), muchas veces extrapolando la información disponible para zonas cercanas. $^{8}$

Al momento de considerar los diezmos y otras rentas propiamente eclesiásticas, los autores siguieron el esquema propuesto por José Luis Martín

\footnotetext{
${ }^{8}$ Ambos autores remiten a los trabajos de José Luis Martín (1993b; 1993c) sobre la documentación zamorana.
} 
(1993a) e indagaron aspectos como el origen de dicho tributo, los productos sujetos a su cobro y su distribución entre los beneficiarios. Consideraron temas que eran de sobra conocidos por los medievalistas, tales como la justificación del diezmo (VILLAR GARCÍA 1986, p. 515-517), la repartición del mismo al interior del cabildo (BARRIOS GARCÍA 1983/84, p. 271), su importancia en la estructura diocesana renovada tras la intervención papal (VILLAR GARCÍA 1986, p. 564 y ss.), etc; en definitiva, aspectos que hacían al funcionamiento institucional de la diócesis. Por otro lado, los autores consideraron los testimonios de resistencia o evasión (BARRIOS GARCÍA 1983/84, p. 268; VILLAR GARCÍA 1986, p. 519522), casi siempre como signo de la progresiva generalización de dicha renta. Sólo Martínez Sopena consideró el problema del trasvase de las iglesias propias a control episcopal (MARTÍNEZ SOPENA 1985, p. 273-304), lo cual es lógico, dado que al sur del Duero la nobleza no pudo recrear el dominio tal y como se encontraba en los territorios del norte.

Esas tesis constituyeron hitos importantes para el conocimiento de la feudalización de la Extremadura histórica. Aun así, queda pendiente conocer mejor la estructura del señorío episcopal, la cual continúa demasiado asimilada a la de los abadengos monásticos, especialmente en cuanto a las dinámicas de su constitución (donaciones pías) y al peso que se confiere a la propiedad de la tierra para su reproducción ${ }^{9}$. Para comprender el proceso de constitución de la Iglesia moderna es necesario centrar la observación nuevamente en la conformación del señorío catedralicio. Dicha institución generó una estructura renovada a partir de la constitución de los episcopados, que le permitió recomponer sus bases económicas. El análisis de una forma señorial específica debe tener en cuenta las variables que Duby mencionaba: dimensión del señorío, formas de gestión, naturaleza y origen de las rentas, formas de percepción... Poseemos gran cantidad de estudios sobre la estructura política del sistema concejil, muchos de ellos datan de los años 90 (probablemente el hecho de que la propiedad dominical no juegue allí un rol relevante condujo a los historiadores a indagar en detalle esa forma de señorío "enteramente político"). Mucho menos se ha dicho sobre las catedrales, segunda forma señorial en importancia en el área. Aunque conocemos bastante bien su dimensión territorial, aún sabemos poco sobre la evolución de la jurisdicción eclesiástica. Se puede suponer que era el paso siguiente en la investigación, pero los años 1990 heredaron de la década anterior otras preocupaciones que dirigieron la investigación hacia problemas diferentes.

\section{Las tesis sobre la dimensión territorial de la sociedad medieval}

La aparición de la obra de Toubert abrió el camino a una serie de estudios en los cuales las transformaciones del hábitat son entendidas como fenómenos de historia total (CURSENTE 2008, p. 72). Poco a poco, tras la aparición de su tesis sobre el Lacio en 1975, el tema de la expresión territorial de los poderes feudales

${ }^{9}$ En uno de sus últimos trabajos, Ángel Barrios García sintetizó su opinión acerca de la feudalización de Ávila. Sus opiniones no difieren en sustancia de lo que hallábamos en su tesis. Ver: BARRIOS GARCÍA 2000. 
fue adquiriendo cada vez más relevancia conceptual. Hoy en día se entiende que "el modelo de poblamiento refleja la sociedad y por ello en sí mismo sirve como testimonio de su historia social" (CURSENTE 2008, p. 72). La tesis de Toubert fue el punto de partida para una serie de trabajos que, en estrecho contacto con los cada vez más abundantes resultados de la arqueología medieval, analizaron diferentes fenómenos de organización del espacio. Primero los castillos, luego las villas castrales y las formas de hábitat disperso y, finalmente, las parroquias y sus cementerios, fueron concebidos como ordenadores del espacio y la vida de los hombres.

Casi al mismo tiempo, la aparición de la obra de Guerreau contribuía a dirigir la atención de los historiadores hacia el rol de la Iglesia en la sociedad medieval. Dicho autor argumentaba que, frente a un Occidente medieval caracterizado por la disgregación del poder político, la única institución que unificaba a la sociedad era la Iglesia. Aún más, dicha institución dominaba todos los ámbitos de la sociedad, ningún aspecto importante escapaba a su control (GUERREAU 1984, p. 229 y ss.). Guerreau asumía los cambios en los intereses historiográficos de la escuela de Annales $^{10}$ y contribuía decisivamente al viraje hacia ámbitos de investigación cada vez más lejanos a las relaciones sociales, en una tendencia que domina hasta ahora (CURSENTE 2008, p. 69). Aunque en Toubert las estructuras eclesiásticas no poseían mayor relevancia, pues se entendían en el marco de procesos más generales, en los historiadores posteriores la dinámica de autoafirmación de la Iglesia adquiere un lugar prioritario (LAUWERS 2009, p. 288-290).

Ambas influencias potenciaron una renovada atención hacia las parroquias rurales. La propuesta de Robert Fossier, sobre todo, subrayó su importancia al destacar su rol en la articulación del marco local, propiciando el anclaje definitivo de la comunidad de los vivos por medio del control del lugar de reposo de los muertos (FOSSIER 1984, p. 242 y ss.). La propuesta del "enceldamiento", que puede aplicarse a diferentes unidades de hábitat, tuvo y tiene amplia acogida entre los medievalistas dado que otorga herramientas para explicar el proceso de sujeción del campesinado sin aludir a problemas como la revolución feudal, eludiendo, de esa forma conceptos clásicos de la historia social que se aproximaban demasiado a las problemáticas del marxismo. Así, la historia social se distanció del problema de las relaciones sociales, acercándose al estudio de "los poderes" en su dimensión territorial. Los "poderes" se entienden en sentido amplio e indeterminado: poderes reales y/o simbólicos, pequeños y grandes, más o menos institucionalizados y cuyo anclaje territorial y peso sobre comunidades e individuos resulta prioritario esclarecer. Se trata de un ámbito mucho menos definido, que aporta conocimientos sobre diversos aspectos, pero que desenfoca el problema de la explotación.

Hoy en día se afirma sin pudor que "la religión fue el verdadero núcleo de toda la sociedad medieval" (CURSENTE 2008, p. 69) y, por lo tanto, se releen

\footnotetext{
${ }^{10}$ Sobre la trayectoria de Annales a partir de 1968 y la influencia de Foucault en el viraje, ver: FONTANA 2001, p. 285-327. A partir de dicho viraje se produjo un acercamiento a cierta corriente "progresista" de la historia de la Iglesia, impulsada por el Concilio Vaticano II, ver: LAUWERS 2008, p. 276-279.
} 
los problemas básicos de dicha sociedad en clave religiosa. Así, por ejemplo, la reforma gregoriana adquiere una relevancia que no hubieran osado soñar los historiadores de principios de siglo: algunos autores han llegado a afirmar que esa reforma transforma la relación entre aristocracia laica y eclesiástica, dando origen al señorío banal (LAUWERS 2009, p. 288; MAZEL 2008, p. 8). Sin ir tan lejos, el conocimiento sobre la influencia eclesiástica en la organización del hábitat es un tema de gran actualidad. La parroquia se encuentra en el centro de los estudios sobre organización social del espacio (BOISSELLIER 2006; GRELOIS 2010; IOGNA-PRAT; ZADORA-RIO 2005; LAUWERS 2008, p. 289; 2010). En el ámbito ibérico, que contaba con los aportes que oportunamente realizara García de Cortázar sobre la organización del espacio; ${ }^{11}$ esta problemática obtuvo una gran recepción en trabajos que apuntan a esclarecer los procesos de configuración espacial de los poderes eclesiásticos. Para eso, se indagan las vías de la territorialización de la parroquia y la diócesis en Santiago de Compostela (LÓPEZ ALSINA 2002. SÁNCHEZ PARDO 2010), Oviedo (CALLEJA PUERTA 2000) o León (CALLEJA PUERTA 2010).

A medida que transcurren los años, la influencia de la historiografía francesa es cada vez más acusada: resulta patente que, mientras los trabajos de principios del siglo actual conservaban cierta distancia de los postulados más cercanos a la "renovación" historiográfica francesa, ${ }^{12}$ diez años después el acercamiento es evidente: el propio García de Cortázar reconoció recientemente su deuda hacia los historiadores franceses para el tratamiento de la dinámica espacial influenciada por la Iglesia. ${ }^{13}$ Esas visiones se encuentran, como es evidente, en las antípodas del pensamiento historiográfico clásico. Cada vez más influidos por las propuestas francesas, los análisis sobre las parroquias medievales ya no se enmarcan en la problemática básica de la sociedad feudal (el señorío como medio de explotación del campesinado), sino que se estudian con ánimos de conocer la implantación del poder de la Iglesia, el cual se caracteriza, en última instancia, como eminentemente espiritual.

\section{Balance final, o una propuesta (no tan nueva) para abordar el problema}

Frente a esta evolución de la historiografía dominante, el abordaje de las estructuras básicas del señorío episcopal requiere una vuelta a las propuestas de la historiografía social clásica, pero que parta de un reconocimiento crítico de los aportes mencionados. Como se ha puesto en evidencia a lo largo de estas páginas, creemos que las consideraciones de Duby poseen aún mucho interés para el análisis empírico. En especial deben retomarse sus ideas en cuanto a la composición de la renta, factor que se ha pretendido destacar en este trabajo,

\footnotetext{
${ }^{11}$ El interés por el rol de los monasterios como organizadores del espacio ya se encuentra en la tesis del autor, quien siguió indagando esos problemas durante los años 80 y 90 (GARCÍA DE CORTÁZAR; MARTÍNEZ SOPENA 2008, p. 106-107).

12 Por ejemplo, Calleja Puerta afirmaba en 2000 que su objetivo era "considerar la concreción territorial de las formaciones parroquiales [...] como reflejo de la articulación de la sociedad y de los distintos ritmos y modalidades del poblamiento, el control social y la atribución de la renta" (CALLEJA PUERTA 2000, p. 25).

${ }^{13}$ Le interesa "analizar el proceso y el resultado del mismo visible en el espacio del esfuerzo desarrollado por la Iglesia católica por implantarse, dirigir y controlar la sociedad de la Europa occidental" (GARCIA DE CORTÁZAR 2010, p. 293).
} 
que busca llamar la atención sobre el lugar del diezmo en la renta catedralicia. Eso no significa desconocer, por ejemplo, los procesos de territorialidad de la parroquia que hoy en día ocupan a muchos medievalistas. Aun así, el análisis debe estar guiado por una crítica a los presupuestos de las tesis que entienden que conocer los fenómenos de territorialidad equivale a acceder a la historia total.

El eje rector del análisis debe retornar al señorío como forma de dominación. En el caso de la nobleza eclesiástica, específicamente del clero secular (dominante en la Extremadura histórica) debe comprenderse, en primer término, el proceso que permitió la participación episcopal en los recursos de las parroquias. En este punto, además de considerar las relaciones al interior de la clase noble [las donaciones de iglesias no implicaron, por lo general, pérdida del control señorial sobre los templos (DIAGO HERNANDO 1997, p. 627-634)], es necesario considerar las relaciones entre las clases. Las comunidades campesinas también fueron propietarias de iglesias y la intervención de la jerarquía eclesiástica en ellas adquirió formas particulares. Como ejemplo, poseemos el trabajo de Loring García sobre las iglesias de particulares en la Liébana de los siglos IX al XI (LORING GARCÍA 1987), del cual surge claramente la necesidad de tener en cuenta la complejidad de los regímenes de propiedad y la estructura social en la que pretendían intervenir las autoridades eclesiásticas (LORING GARCÍA 1987, p. 101-102). Asimismo, la conflictividad en torno a esos procesos de absorción de derechos o a la generalización del diezmo debe entenderse como elemento constante, fuente de dinamismo y causa de aparición de diversas estrategias por parte de los actores sociales involucrados. Las posibilidades de un trabajo orientado por esas perspectivas se han comprobado recientemente, a partir de un estudio de Isabel Alfonso (ALFONSO 2010). La autora postuló la necesidad de pensar las parroquias no sólo como ámbitos de penetración señorial en el espacio rural, sino también como espacios políticos en disputa que podían ser apropiados por las comunidades campesinas y empleados para articular la resistencia. Criticó así la comprensión "desde arriba" de fenómenos tan complejos como la reforma gregoriana.

Una vez dilucidado el proceso que habilitó a los obispos a participar en las rentas parroquiales, se impone el estudio de la estructura del señorío catedralicio, atendiendo en especial a la composición de la renta. Gracias a los estudios de los años 70 y 80 conocemos bastante bien la dimensión territorial de las fortunas eclesiásticas, pero precisamos avanzar más en la comprensión del peso relativo de otros tipos de rentas, especialmente los diezmos. En un balance reciente, se puso en evidencia que numerosos historiadores los han estudiado en el marco de los más diversos problemas y ya no sólo como medio para conocer las coyunturas agrarias (DÍAZ DE DURANA; GUINOT 2010). Es momento, entonces, de reconsiderar su lugar en el sostenimiento de las Iglesias castellano-leonesas. Sabemos que hasta el siglo XI el señorío de las catedrales no se diferenciaba del de los monasterios (GARCÍA DE CORTÁZAR 1989, p. 267271). Además ha quedado establecido que durante los siglos siguientes la red parroquial se desarrolló considerablemente merced, en parte, a la iniciativa de los obispos, que disputaron tenazmente su participación en la renta decimal. 
Gracias a los estudios de los historiadores modernistas, sabemos que dicha renta no era para nada despreciable (Cf. IBÁÑEZ RODRÍGUEZ 1999, p. 24). Debemos considerar en qué medida el peso de los diezmos supuso una estructura de la renta catedralicia menos basada en la propiedad de la tierra y crecientemente sustentada en la fiscalidad parroquial.

Si la estructura de la renta de monasterios y catedrales hacia fines de la Edad Media era distinta, cabe esperar distintas reacciones señoriales a las coyunturas agrarias, las transformaciones de la estructura política o las presiones de los campesinos. Desde esta base, creemos, será posible comprender la evolución que atravesó el poder eclesiástico en sus formas de dominación, de una Iglesia local, basada en monasterios y sujeta a los poderes territoriales, a una Iglesia crecientemente burocrática (WOOD 2006, p. 904 y ss.), basada en una compleja estructura fiscal. Eso no supone, claro está, minimizar el lugar que la propiedad de la tierra poseyó en la fortuna eclesiástica, pero sí intentar destacar que la detracción indirecta de los recursos del campesinado tuvo un lugar incuestionable y que la eficacia del aparato eclesiástico parece innegable. En ese sentido, es sintomático que todas las demás fracciones de la clase dominante participaran, de una u otra manera, en la renta decimal, que se constituyó en uno de los rubros más importantes de los recursos de los reyes y otros grandes nobles. Es así que nuestro interés en la renta decimal y la "modernización" del aparato de exacción sobre el cual se sustentó el clero secular parece ser un aspecto de primer orden para comprender la reproducción

102 material de las clases dominantes de la sociedad tradicional.

\section{Referencias bibliográficas}

ALFONSO, Isabel. Iglesias rurales en el norte de Castilla: una dimensión religiosa de las luchas campesinas durante la Edad Media. In: GARRABOU, Ramón; ROBLEDO, Ricardo (eds.) Sombras del progreso: las huellas de la historia agraria. Barcelona: Crítica, p. 27-65, 2010.

ASTARITA, Carlos. La historia de la transición del feudalismo al capitalismo en Europa occidental. Anales de Historia antigua, medieval y moderna, v. 41, 2009. p. 101-141.

BARRIOS GARCÍA, Ángel. Estructuras agrarias y de poder en Castilla: el ejemplo de Ávila (1085-1320). Salamanca: Universidad de Salamanca, 1983/84. 2v.

Colonización y feudalización. In: BARRIOS GARCÍA, Ángel et al. Historia de Ávila. Ávila: Institución Gran Duque de Alba, 2000, p. 339-408. v. II.

BIDAGOR, Ramón. La iglesia propia en España. Estudio histórico-canónico. Roma: Pontificia Universitas Gregoriana, 1933.

BOISSELLIER, Stéphane (ed.) De l'éspace aux territoires: la territorialité des processus sociaux et culturels au Moyen Âge. Actes de la table ronde des 8-9 juin 2006, CESCM. Poitiers: Brepols, 2006. 
BOUGARD, François. Genèse et réception du Mâconnais de Georges Duby. Bulletin du centre d'études médiévales d'Auxerre | BUCEMA [En ligne]. Hors-série n. 1, 2008. Disponible en: http://cem.revues.org/4183. Consultado el 16 mar. 2013.

CALLEJA PUERTA, Miguel. La formación de la red parroquial de la diócesis de Oviedo en la Edad Media. Oviedo: Real Instituto de Estudios Asturianos, 2000.

- Eclesiología episcopal y organización del espacio en las ciudades y villas del noroeste peninsular (1100-1250). In: DE LA IGLESIA DUARTE, José Ignacio (coord.). Monasterios, espacio y sociedad en la España cristiana medieval. XX Semana de Estudios Medievales. Nájera, del 3 al 7 de Agosto de 2009. Logroño: Instituto de Estudios Riojanos, 2010, p. $429-490$,

CURSENTE, Benoît. Tendencias recientes de la historia rural de la Francia Medieval. In: ALFONSO, Isabel (ed.). La historia rural de las sociedades medievales europeas: tendencias y perspectivas. Valencia: Universitat de València, 2008, p. 65-95,

DÍAZ DE DURANA, José Ramón; GUINOT, Enric. La dîme dans I'Espagne médiévale. In: VIADER, Roland (ed.). La dîme dans I'Europe médiévale et moderne. Actes de $X X X^{\text {es }}$ Journées Internationales d'Histoire de I'Abbaye de Flaran, 3 et 4 octobre 2008. Toulouse: Presses Universitaires du Mirail, 2010, p. 63-88.

DIAGO HERNANDO, Máximo. Las iglesias propias de monasterios en la Castilla bajomedieval. Algunos ejemplos riojanos. Hispania Sacra, v. 49, n. 100, p. 625-651, 1997.

DUBY, Georges. Économie domaniale et économie monétaire : le budget de I'abbaye de Cluny entre 1080 et 1155 . Annales. Économies, Sociétés, Civilisations, v. 7, n. 2, p. 155-171, 1952.

. El señorío y la economía campesina: Alpes del sur, 1338. In:

Hombres y estructuras de la Edad Media. Madrid: Siglo XXI, 1977 [1961], p. 79-119.

. Economía rural y vida campesina en el Occidente medieval. Madrid: Altaya, 1999a.

Guerreros y campesinos: desarrollo inicial de la economía europea (500-1200). Madrid: Siglo XXI, 1999b.

DUMAS, Auguste. Les églises paroissiales. In: AMANN, Emile; DUMAS, Auguste. L'Église au pouvoir des laïques (888-1057). París: Bloud \& Gay, 1948. FONTANA, Josep. La historia de los hombres. Barcelona: Crítica, 2001.

FOSSIER, Robert. La infancia de Europa: siglos X-XII. Aspectos económicos y sociales. Barcelona: Labor, 1984. 
GARCÍA DE CORTÁZAR, José Ángel. El dominio del monasterio de San Millán de la Cogolla (siglos X a XIII): introducción a la historia rural de la Castilla altomedieval. Salamanca: Universidad de Salamanca, 1969.

. Feudalismo, monasterios y catedrales en los reinos de León y Castilla. In: EN TORNO AL FEUDALISMO HISPÁNICO: I CONGRESO DE ESTUDIOS MEDIEVALES, 1989, León. Anales... León: Fundación Sánchez Albornoz, 1989 , p. 259-292.

GARCÍA DE CORTÁZAR, José Ángel; MARTÍNEZ SOPENA, Pascual. Los estudios sobre historia rural de la sociedad medieval hispanocristiana. In: ALFONSO, Isabel (ed.). La historia rural de las sociedades medievales europeas: tendencias y perspectivas. Valencia: Universitat de València, 2008, p. 97-143.

GUERREAU, Alain. El feudalismo: un horizonte teórico. Barcelona: Crítica, 1984.

IBÁÑEZ RODRÍGUEZ, Santiago. El pan de Dios y el pan de los hombres: diezmos, primicias y rentas en la diócesis de Calahorra (ss. XVI-XVIII). La Rioja: Universidad de La Rioja, 1999.

IMBART DE LA TOUR, Pierre. Les origines religieuses de la France: les paroisses rurales du IV au XI ${ }^{\mathrm{e}}$ siècle. Paris: Alphonse Picard et fils, 1900.

IOGNA-PRAT, Dominique; ZADORA-RIO, Elisabeth. Formation et transformations 104 des territoires paroissiaux. Médiévales: Langue, textes, histoire. Paris, n. 49, 2005. Dossier. Disponible en: http://medievales.revues.org/1200. Consultado el: 21 abr. 2013.

LAUWERS, Michel. L'Église dans I'Occident médiéval: histoire religieuse ou histoire de la société? Quelques jalons pour un panorama de la recherche en France et en Italie au XXe siècle. Melanges de I'École française de Rome. Moyen Age, n. 121, p. 267-290, 2009.

. Circuit, cimetière, paroisse. Réflexions sur l'ancrage ecclésial des sites d'habitat (VII ${ }^{\mathrm{e}}$-XIII ${ }^{\mathrm{e}}$ siècle). In: YANTE, Jean-Marie; BULTOT-VERLEYSEN, Anne-Marie (eds.). Autour du «village». Établissements humains, finages et communautés rurales entre Seine et Rhin (IVe-XIII siècles). Louvain-la-Neuve: Université catholique de Louvain, 2010, p. 301-324.

LE BRAS, Gabriel. Pour l'étude de la paroisse rurale. Revue d'histoire de I'Église de France, n. 101, p. 486-502, 1937.

LÓPEZ ALSINA, Fernando. El encuadramiento eclesiástico como espacio de poder: de la parroquia al obispado. In: DE LA IGLESIA DUARTE, José Ignacio (coord.); MARTÍN RODRÍGUEZ, José Luis (dir.). Los espacios de poder en la España medieval. XII Semana de Estudios Medievales. Nájera: Instituto de Estudios Riojanos, 2002. p. 425-457.

LORING GARCÍA, María Isabel. Nobleza e iglesias propias en la Cantabria altomedieval. Studia Historica. Historia Medieval, n. 5, p. 89-121, 
1987.

MAZEL, Florian. Pouvoir aristocratique et Église aux $\mathrm{X}^{\mathrm{e}}-\mathrm{XI} \mathrm{I}^{\mathrm{e}}$ siècles. Retour sur la «révolution féodale» dans I'œuvre de Georges Duby. Bulletin du centre d'études médiévales d'Auxerre | BUCEMA [En ligne]. Hors-série n. 1, 2008. Disponible en: http://cem.revues.org/4183. Consultado el: 16 mar. 2013.

MARTÍN, José Luis. Diezmos eclesiásticos. In:

Amor, cuestión de

señorío y otros estudios zamoranos. Zamora: Universidad Nacional de Educación a Distancia, 1993a [1975], p. 53-62.

. Campesinos vasallos de la iglesia de Zamora en los siglos XII y XIII. In: Amor, cuestión de señorío y otros estudios zamoranos. Zamora: Universidad Nacional de Educación a Distancia, 1993b [1977], p. 63-76.

Campesinos vasallos del obispo Suero de Zamora. In:

Amor, cuestión de señorío y otros estudios zamoranos. Zamora: Universidad Nacional de Educación a Distancia, 1993c [1981], p. 77-95.

MARTÍNEZ SOPENA, Pascual. La Tierra de Campos occidental: poblamiento, poder y comunidad del siglo $\mathrm{X}$ al XIII. Valladolid: Institución Cultural Simancas, 1985.

MORÁN MARTÍN, Remedios. Eduardo de Hinojosa y los estudios de historia del derecho en España después de su muerte: Manuel Torres López. Edición y reconstrucción. E-legal history review, n. 0, 2005. Disponible en: http://www.iustel.com/v2/revistas/detalle_revista.asp?id_ noticia $=403851 \& d=1$. Consultado el: 3 feb. 2013.

REGLERO DE LA FUENTE, Carlos. Un género historiográfico: el estudio de dominios monásticos en la Corona de Castilla. In: DE LA IGLESIA DUARTE, José Ignacio (coord.). Monasterios, espacio y sociedad en la España cristiana medieval. XX Semana de estudios medievales. Nájera, del 3 al 7 de Agosto de 2009. Logroño: Instituto de Estudios Riojanos, 2010, p. 33-75.

RODRÍGUEZ GIL, Magdalena. Consideraciones sobre una antigua polémica: las Iglesias propias. Cuadernos de Historia del Derecho, n. 6, p. 247-272, 1999.

SÁNCHEZ PARDO, José Carlos. Las iglesias rurales y su papel en la articulación territorial de la Galicia medieval (ss. VI-XIII). In: Mélanges de la Casa de Velázquez [En ligne], 40-1 | 2010. Disponible en: http://mcv.revues. org/3374. Consultado el: 12 oct. 2012.

STUTZ, Ulrrich. Geschischte des kirchlichen Benefizialwesens von seinen Anfängen bis auf die Zeit Alexanders III. Berlim: H.W. Müller, 1895a.

Die Eigenkirche als Element des mittelalterlich: germanischen Kirchenrechts. Berlim: H.W. Müller, 1895b. 
THOMAS, Paul. Le droit de propriété des laïques sur les églises et le patronage laïque au moyen âge. Paris: Ernest Leroux, 1906.

TORRES LÓPEZ, Manuel. La doctrina de las «iglesias propias» en los autores españoles. Anuario de Historia del Derecho Español, n. 2, p. 402461, 1925.

. El origen del sistema de «iglesias propias». Anuario de Historia del Derecho Español, n. 5, p. 83-217, 1928.

TOUBERT, Pierre. Prefacio a Les caractères originaux de I'histoire rurale française de Marc Bloch. Argumentos, n. 26, p. 59-90, 1997.

VIARD, Paul. Histoire de la dîme ecclésiastique principalement en France jusqu'au décret de Gratien. Dijon: Jobard, 1909.

VILLAR GARCÍA, Luis Miguel. La Extremadura castellano-leonesa: guerreros, clérigos y campesinos (711-1252). Valladolid: Junta de Castilla y León, 1986.

WOOD, Susan. The Proprietary Church in the Medieval West. Oxford: Oxford University Press, 2006. 